\title{
Mini-review: phytology of Dabai (Canarium odontophyllum) as a potential functional food
}

\author{
${ }^{1}$ Mundi, M., ${ }^{1}$ Rawi, M.H., ${ }^{1}$ Saupi, N. and ${ }^{1,2, *}$ Sarbini, S.R. \\ ${ }^{I}$ Department of Crop Science, Faculty of Agricultural Science and Forestry, Universiti Putra Malaysia \\ Bintulu Campus, 97008, Sarawak, Malaysia \\ ${ }^{2}$ Halal Products Research Institute, Universiti Putra Malaysia, Putra Infoport, 43400, UPM Serdang, \\ Selangor, Malaysia
}

\section{Article history:}

Received: 30 December 2020

Received in revised form: 22

February 2021

Accepted: 29 May 2021

Available Online: 31 January

2022

Keywords:

Dabai,

Borneo,

Superfruit,

Antioxidant,

Dietary fibre,

Indigenous

\section{DOI:}

https://doi.org/10.26656/fr.2017.6(1).775

\begin{abstract}
By having large sources of fruits and vegetables, Sarawak, Malaysia has a remarkable diversity of flora. One of the underutilised local indigenous fruits in Sarawak that come from the Burseraceae family is Dabai (Canarium odontophyllum). Dabai is highly nutritious and rich in protein, fat, energy and carbohydrate. Hence, the oil extraction of nutritive dabai has become one of the interests in this review. The chemical characteristics of the extracted oils from both the dabai flesh and the kernel were discussed. A total of approximately 75 recognised species have been found mainly in Asia, the Pacific and tropical Africa. Later led to further investigation of the possible cholesterol-lowering agent due to its high antioxidant ability. The fruit is slightly triangular in the cross-section, ovoid to ellipsoid. It is also rich in phenolic compounds and vitamin E, such as $\gamma$ tocopherol. The review uncovered the potentials of the dabai as nutritious fruit with promising medicinal properties.
\end{abstract}

\section{Introduction}

Dabai (Canarium odontophyllum) which comes from the Burseraceae family is one of the underutilised local indigenous fruits in Sarawak, Malaysia (Figure 1). Dabai fruit, a savoury dish, is prepared by soaking in warm water from 5 to 10 minutes to soften the skin and flesh and consumed directly on its own or with rice, usually flavoured with salt or soy sauce (Figure 2). The oil-rich seed is usually discarded but also can be eaten as a nut, upon further boiling for 10 minutes. Dabai contains a rich source of protein, fat, carbohydrates and minerals like sodium, calcium and iron (Shakirin et al., 2012b). Dabai is highly demanded due to its natural delicious creamy and 'fatty' taste almost similar to avocado, being exotic and unique to Sarawak, and also its high nutritional properties.

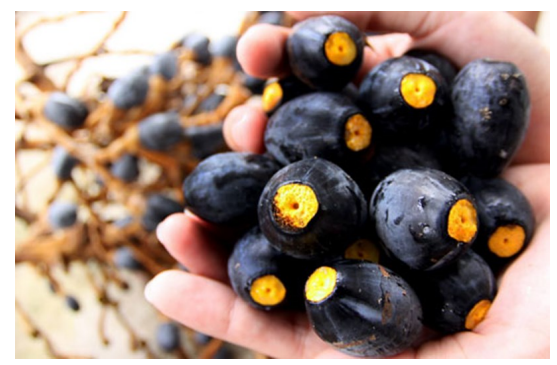

Figure 1. Dabai is often called "Sarawak olive" because it appears like an olive and has hard seed inside (Emmet, 2017).

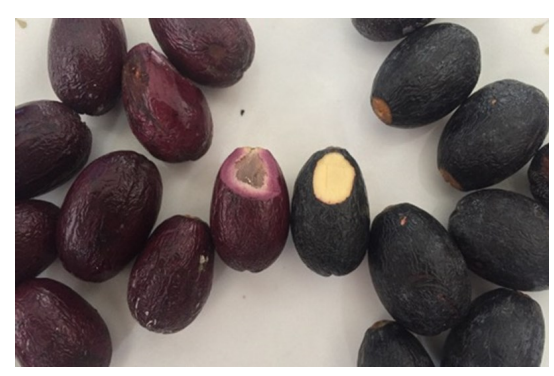

Figure 2. Raw dabai (right) and cooked dabai (left). Both skin and flesh turned red from black and yellow respectively after being boiled for 10 mins.

Altogether around 75 recognised species of dabai can be found in Asia, the Pacific, and tropical Africa (Leenhouts et al., 1956). In Asia, it can be found in the land of Borneo Malaysia, Brunei, Kalimantan, Sumatera Indonesia, and Palawan in the Philippines. Dabai is a seasonal fruit and are abundant in Sibu, a town in Sarawak, Malaysia and is one of the six most highly appreciated indigenous fruit in the land of Sarawak that possesses the potential for commercialisation purposes (Voon, 2003). A few value-added products have also been developed by the Department of Agriculture of Sarawak in the attempt to fully utilise and commercialise dabai to the market, for example, incorporated into mayonnaise, fried rice, pitted dabai, dabai sauce and ice 


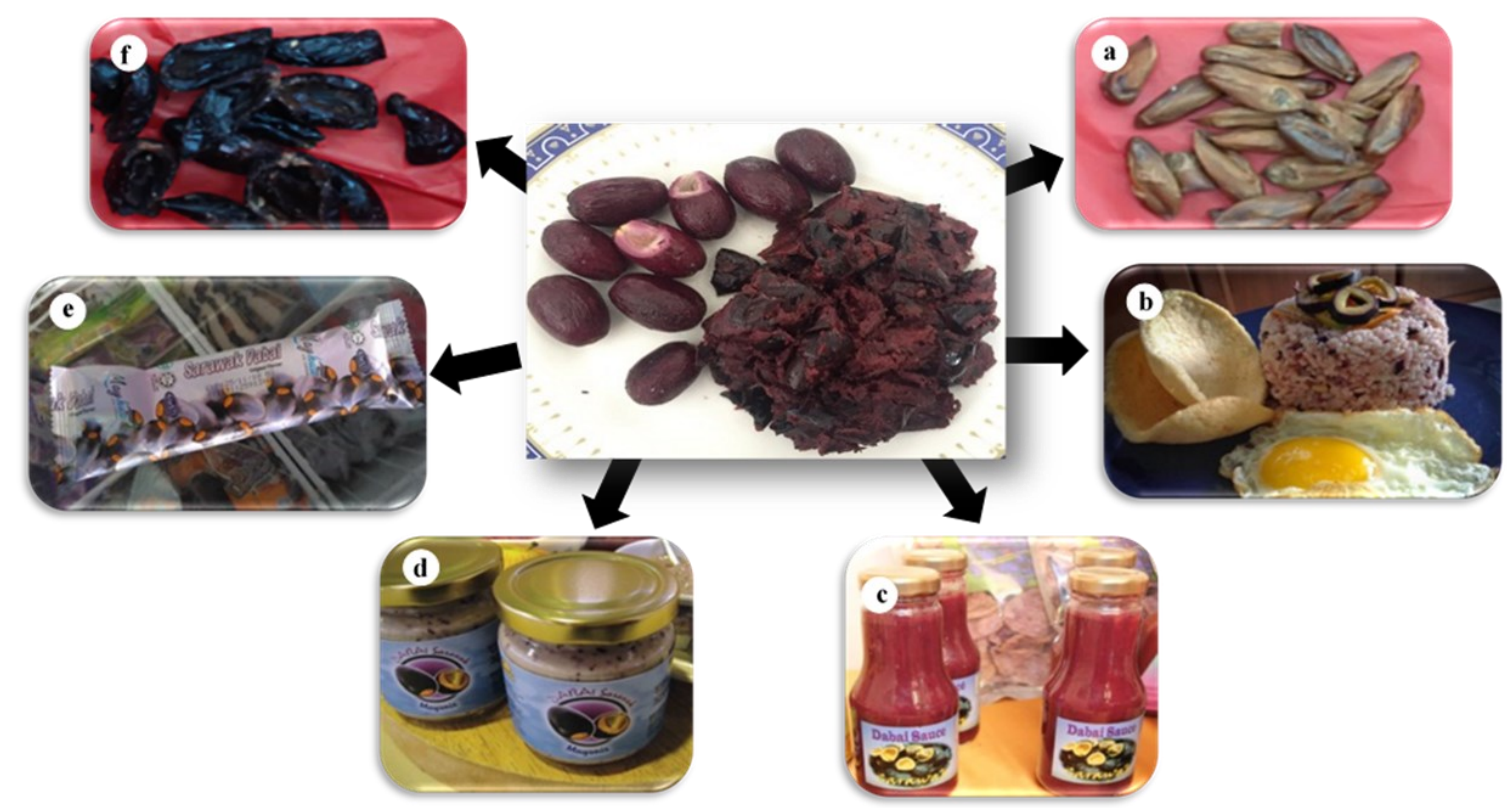

Figure 3. Food products incorporated with dabai. a) Dabai nut (NCL GoldenTrove Sdn Bhd, 2012), b) Dabai fried rice (Nimi, 2013), c) Dabai sauce (Fazlisham, 2010), d) Dabai mayonnaise (Malaysian Agricultural Research and Development Institute (MARDI), 2017), e) Dabai ice cream (Nayra, 2017), f) Dried dabai (NCL GoldenTrove Sdn Bhd, 2012).

cream (Figure 3). As shown in Figure 4, dabai fruit is vastly cultivated in the Sibu and Kapit Divisions, Sarawak, Malaysia (Hoe and Siong, 1999). Relatively pest and disease-free fruit, it has the advantage to be produced under the Integrated Fruit Production (IFP) system to prevent potential problems from occurring in commercial cultivation (Lau, 2011).

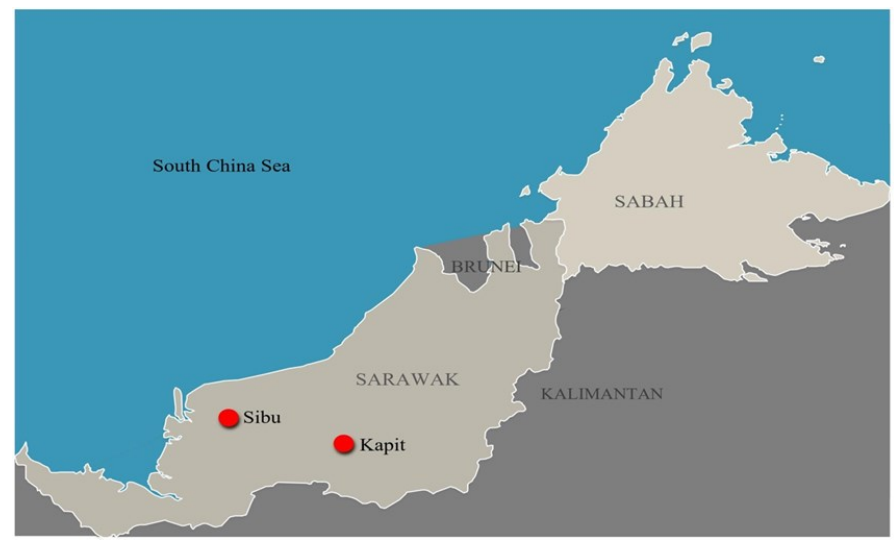

Figure 4. Sibu and Kapit divisions are the main dabai production area in Sarawak state.

Since 2006, two superior dabai clones are made available, namely Dabai Laja and Dabai Lulong with their vigorous growth just after five years they start to bear fruits. In terms of size, the fruit of 'Laja' is bigger with an individual fruit weight of $18.9 \mathrm{~g}$ (Lau and Voon, 2007). These dabai clones are also reported as rich in fat and carbohydrate. There are other dabai varieties such as 'Song', 'Kapit', 'Intermediate', 'Egg Yolk', 'Tarat', 'Red Dabai' and 'Pulau Keladi' (Brooke and Lau, 2013). Harvesting season is usually from November to January and made available at the local market with the fluctuating price due to overall limited availability and its short shelf life due to its high respiration rate. Dabai fruits can fetch premium prices at the beginning and towards the end of the harvesting season (Malaysian Agricultural Research and Development Institute (MARDI), 2017). Young dabai trees that started to bear fruit usually yield low at 10-20 kilogram/tree. However, at maturity ( $>10$ years), the yield may reach up to 50 $300 \mathrm{~kg} /$ tree in a given season. The dabai price varies greatly depending on the season (weather pattern affecting yield), quality and demand. Where availability of dabai is scarce, higher price range from RM14 to well over RM28 per kilogram. Whereas, during the peak season, the price of dabai could drop to RM5 or less for every kilogram (Brooke et al., 2013).

Normally, dabai have a shelf life of three days when kept in room temperature $\left(27^{\circ} \mathrm{C}\right)$, later than that it will start to wrinkle (Figure 5) due to dehydration (Ding and Tee, 2011). These changes to appearance reduce the palatability before it continues to deteriorate. Since this fruit has a similar appearance to olive (Figure 6), thus it is considered an ovoid drupe. It is slightly triangular in cross-section, ovoid to the ellipsoid (Lemmens et al., 1995). The size varies from 35 to $40 \mathrm{~mm}$ long and 20 to $25 \mathrm{~mm}$ wide. It has yellow aril, dark purple to blackish exocarp, and a hard endocarp with an edible seed. Peer reviewed studies on dabai have shown multiple evidence suggesting the benefit of extracted compounds from various parts of the plants. Therefore, this mini review discussed the collections of literature on the nature of dabai and its physicochemical properties. The topics were arranged to elaborate the botanical characteristics, nutritional content and functional properties, health implication, and illustrate few possible upstream and downstream developments of dabai derivatives to valueadded products. 


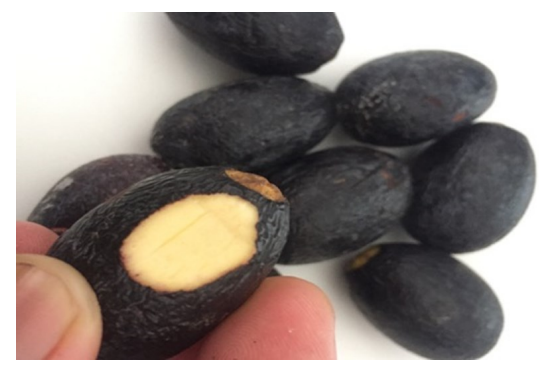

Figure 5. Wrinkles due to dehydration can be seen after three days stored in room temperature, $27^{\circ} \mathrm{C}$.

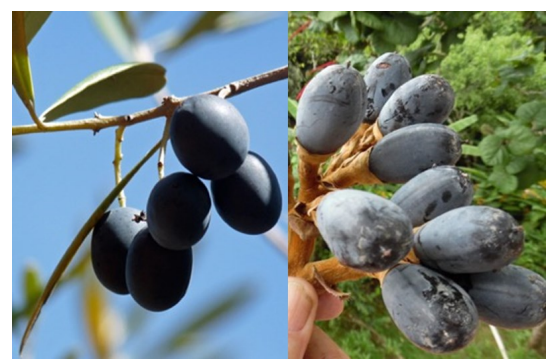

Figure 6. Side to side comparison of ripe dabai (right) resembling ripe olives (left) (McCauley, 2010; Machabuca, 2015).

\section{Botanical characteristics}

Mature dabai fruit is normally purplish to black colour while immature dabai is white. There are some rare dabai which is red and can be found in Sarikei, Sarawak. Dabai tree is resiniferous, monoecious and can grow up to 25 metres high with a girth of up to $60 \mathrm{~cm}$ (Sim and Lau, 2011), as shown in Figure 7. Dabai tree can be found mostly in its native tropical range such as hillsides, ridges and sometimes swamps and riversides (Lim, 2012). It has three to eight jugate oblong leaves. On the bottom of the leave, it may have tiny pilose to thick tomentose with a short and slender apex as shown in Figure 8.

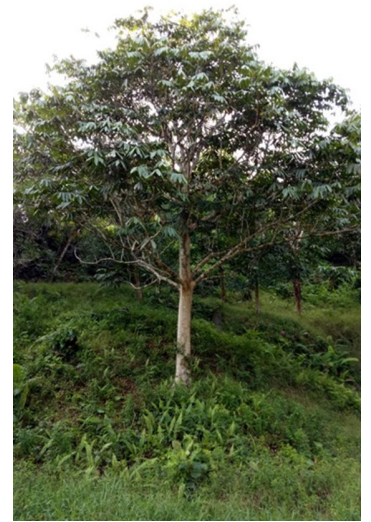

Figure 7. A dabai tree by the road side at Kapit, Sarawak

The arrangement of nerves on the leaf is slightly sunken on the top but heavy on beneath. It has roughly 15 to 28 pairs ranging from straight to curly nerves. Dabai tree has inflorescences axillary and is about 30 to $50 \mathrm{~cm}$ long with numerous flowers in male tree whereas, in female tree, it is around 15 to $20 \mathrm{~cm}$ long with just a few flowers. These flowers are white-yellow in colour and have pubescent outside of them. The receptacle of

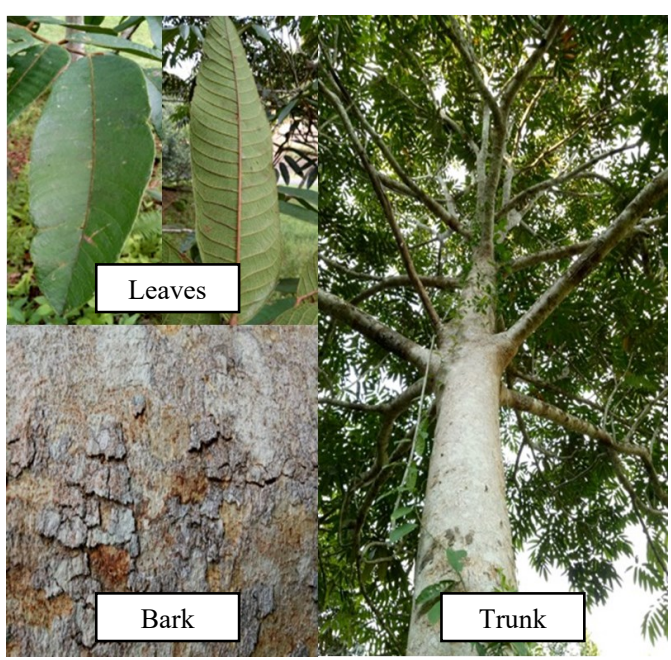

Figure 8. Images of dabai leaves (top left), bark (bottom left) and trunk (right).

dabai tree is slightly concave in shape. Beneath the flower, it has three-parted sepal or also known as calyx with different lengths. In male, it is longer with 2.5 to 4.5 $\mathrm{cm}$ whereas in female it is only $8 \mathrm{~mm}$ high. Besides, the stamens and disk are glabrous. During fertilization, the ovary contains fertilized ova and starts to swell and eventually grow bigger through a process called ripening.

Dabai fruit is differentiated into respective anatomy namely skin (peel), flesh, and seed as seen in Figure 9. As in Figure 10, it generally contains $5.6 \%$ of skin, $61.4 \%$ of flesh, and $37 \%$ of seed (Azrina et al., 2010). The flesh of dabai fruit has a thickness of 4 to $7 \mathrm{~mm}$ which covers a three-angled pointed single large seed. A well quality dabai fruit should weigh around $18 \mathrm{~g}$, and has a texture that is fine with a nutty flavour. The seed is usually discarded by most people. Seed propagation is not recommended; asexual methods should be used instead. Seed propagation may result in fruits with variable traits and would give male trees which do not produce fruit. Two selection of superior clones were identified by the Research Division of the Department of Agriculture Sarawak, namely Laja and Lulong which are highly recommended for commercial planting. The growth of these clones from vegetative propagation (budding method) is vigorous and they begin to bear fruits five years after planting. The initial yield is about $10 \mathrm{~kg}$ per tree and can gradually increase to $80-100 \mathrm{~kg}$

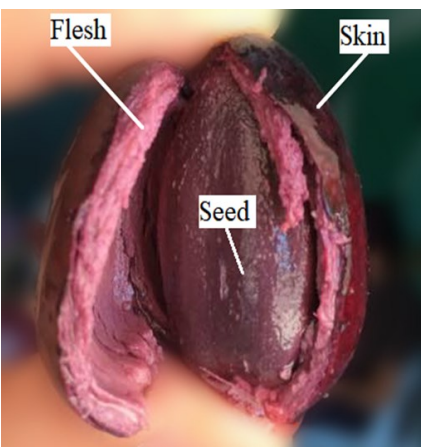

Figure 9. Shows the skin, flesh and seed of a dabai fruit.

C 2022 The Authors. Published by Rynnye Lyan Resources 
per tree when the tree reaches 10 years and above (Brooke and Lau, 2013). With an economic lifespan of about 40 years, dabai farming offers a satisfactory return value in the long run.

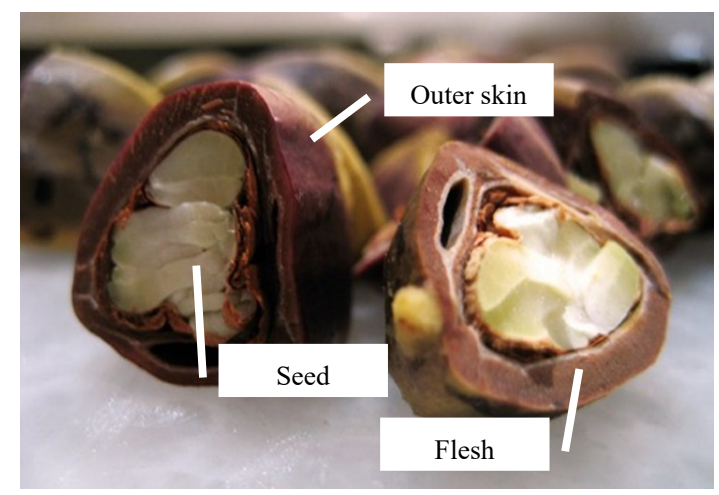

Figure 10. Cross-section of the triangular shape fruit showing flesh is the major components followed by the seed and outer skin (Cometh, 2008).

\section{Nutritional content and functional properties}

An undeniable fact about dabai fruit is that it is nutritive and contains medicinal properties. Dabai fruit is highly nutritious and is rich in protein, fat, energy and carbohydrate (Hoe and Siong, 1999). It is also high in phenolic compounds and vitamin E such as $\gamma$-tocopherol (Shakirin et al., 2012a). In recent years, due to the high nutritional quality, the fruit of dabai had been promoted as a speciality fruit by the DOA Sarawak (Lau, 2009).

The chemical characteristic of extracted oils from both dabai flesh and kernel were determined to discover any commercial use of these extracted oils. The chemical characteristics that been quantified were acid, peroxide, iodine and saponification values. Soxhlet method was used to extract the oil from both flesh and kernel of dabai where the crude oil did not undergo any refining processes. For the flesh of dabai, it has been determined to contain about $8.4 \mathrm{mg}$ of $\mathrm{KOH}$ for acid value, $7.99 \pm 0.01 \mathrm{mEq}$ peroxide $/ \mathrm{kg}$ for peroxide value, $52.8 \pm 1.48 \mathrm{~g}$ of iodine $/ 100 \mathrm{~g}$ fat for iodine value, and $181.62 \pm 0.99 \mathrm{mg}$ of $\mathrm{KOH} / \mathrm{g}$ fat for saponification value. For the kernel, it has $5.55 \pm 0.02 \mathrm{mg}$ of $\mathrm{KOH}$ for acid value, $16.0 \pm 0.07 \mathrm{mEq}$ of peroxide $/ \mathrm{kg}$ fat for peroxide value, $37.7 \pm 0.14 \mathrm{~g}$ of iodine $/ 100 \mathrm{~g}$ fat for iodine value, and $171.33 \pm 1.05 \mathrm{mg}$ of $\mathrm{KOH} / \mathrm{g}$ fat for saponification value (Azlan et al., 2010). According to the study, these properties were comparable to commercial palm and olive oil. The dabai flesh oil gives the yellowish colour that the physicochemical properties of this oil are closer to olive oil. Dabai flesh oil had high acid values for acid content, which could be due to the presence in crude oils of large amounts of free fatty acids. However, because these oils were in refined form, the commercial palm and olive oils examined had less acid content. The method of refining extracts all free fatty acids before. Oil with a peroxide content below $30 \mathrm{mEq}$ peroxide $/ \mathrm{kg}$ has typically been considered safe for human consumption. It can therefore be inferred that both Dabai oils have strong oxidation stability. It should also be noted that the peroxide value of dabai flesh oil was less than $15 \mathrm{mEq}$ of peroxide per $\mathrm{kg}$ of oil, well below the defined standard by Food and Drug Administration (FDA)/World Health Organisation (WHO) under the Codex Alimentarius Commission (2019). Low iodine content is always associated with good quality and longer shelf life that could prevent oxidative deterioration. The high saponification value is beneficial for dabai oils when undergoing hydrogenation, it could be used as an alternative for some conventional oils in soap and shampoo manufacturing.

Apart from the chemical characteristic of oils extraction, the content of vitamin $\mathrm{C}$ from both flesh and skin are also determined. It has $2.59 \pm 0.01 \mathrm{mg}$ of vitamin $\mathrm{C} / 100 \mathrm{~g}$ from flesh whereas the skin has $5.85 \mathrm{mg}$ of vitamin $\mathrm{C} / 100 \mathrm{~g}$ respectively. From the obtained results, the extracted oils from dabai are much similar to palm oil which are recommended as edible oil. Besides, the vitamin $\mathrm{C}$ content of dabai is similar to olive fruit which can be commercialized as well. Apart from that, carotenoids are being studied and determined from skin, flesh and kernel respectively. Carotenoids can lower the risk of acquiring diseases specifically cancers and eye disease (Johnson, 2002). There are a huge number of known carotenoids thus it is categorized into xanthophylls and carotenes. Xanthophylls are compounds that have oxygen molecules attached whereas carotenes are otherwise.

The skin of dabai has $69.5 \pm 1.0 \mathrm{mg} / \mathrm{kg}$ of all-trans $-\beta-$ carotene followed by $31.1 \pm 0.76 \mathrm{mg} / \mathrm{kg}$ in the flesh, and lastly $15.1 \pm 3.0 \mathrm{mg} / \mathrm{kg}$ in the kernel (Prasad et al., 2011). Apart from all-trans- $\beta$-carotene, there are also 15-cis- $\beta$ carotene, 9-cis- $\beta$-carotene, and 13-cis- $\beta$-carotene in the skin, flesh, and kernel of dabai fruit. A process of determining antioxidant activities known as $\beta$-carotene bleaching are being carried out. Among the skin, flesh, and kernel, the flesh has the greatest $\beta$-carotene bleaching activity due to its high 1,1-diphenyl-2picrylhydrazyl (DPPH) radical activity. The flesh has the highest DPPH radical-scavenging activity compared to the skin and kernel. These extracts depicted great inhibitory effect against oxidation of haemoglobin induced by hydrogen peroxide from $45.3 \%$ up to $59.7 \%$. The average antioxidant properties were tested using DPPH assay which resulted in $16.46 \mathrm{mM}$ Trolox equivalent TE/g for skin, $20.54 \mathrm{mM} \mathrm{TE} / \mathrm{g}$ for the flesh, and lastly $8.89 \mathrm{mM} \mathrm{TE} / \mathrm{g}$ for kernel respectively.

The total average phenolic content for skin, flesh, and kernel is $387.5 \mathrm{mg}$ gallic acid equivalent GAE/100 
g, $267.0 \mathrm{mg} \mathrm{GAE} / 100 \mathrm{~g}$, and lastly $51.0 \mathrm{mg} \mathrm{GAE} / 100 \mathrm{~g}$ respectively where the gallic acid equivalent is the standard to determining phenolic content by analytes using Folin-Ciocalteau assay. From these findings, dabai possess a huge potential source of natural antioxidants and total phenolic content are positively correlated with the antioxidant activities which possible to be exploited as a nutraceutical and functional food industry (Lim, 2012).

In addition to the nutritional value of dabai fruit, it has been proven that extract from dabai is able to lower plasma cholesterol (Mokiran et al., 2014). Low-densitylipoprotein (LDL) can be significantly reduced while increasing high-density-lipoprotein (HDL). The LDL cholesterols are the ones that responsible for various diseases whereas atherosclerosis is one of the malignant disease conditions due to the deposit of plaque and clog the arteries (Shakirin et al., 2012a). The prolonged condition may eventually lead to stroke and heart attack. The HDL cholesterol is the one that assists in removing the amount of LDL found in arteries thus lower level of HDL cholesterol may lead to a higher amount of LDL and cause diseases. An experiment was carried out with two groups of rats that are treated with a high concentration of dabai extract (HiDE) and rosiglitazone (Rosi) which is a drug that acted as a positive control respectively. The result shows that both HiDE and Rosi significantly increase plasma HDL levels by $47 \%$ and $94 \%$ when compared to the untreated group. Levels of plasma LDL were also noticed to be significantly decreased by $55 \%$ and $57 \%$ when compared to the untreated group after 4 weeks of treatment (Mokiran et al., 2014).

Apart from that, there is a potential for antiacetylcholinesterase activity from the extract of the flesh and seed of dabai (Ali-Hassan et al., 2013). Acetylcholinesterase is an enzyme that is responsible for to breakdown of acetylcholine which functions as a neurotransmitter in the nervous system. One of the diseases relevant to acetylcholinesterase is Alzheimer's disease due to the loss of cholinergic neurons. Thus, anticholinesterase drugs are being used for Alzheimer's disease. There are two different studies carried out which are the $80 \%$ methanol extracts and distilled water extracts of the flesh and seed of dabai. An amount of $80 \%$ methanol extracts depicts $22.4 \%$ and $18.6 \%$ of antiacetylcholinesterase activity from flesh and seed respectively while very low $(<1 \%)$ showed from distilled water extraction on both flesh and seed. Flesh oil (fatty acids) composition was comparable to palm oil, due to their near-equal percentage of saturated, monounsaturated fatty acids and also polyunsaturated fatty acids, which are $43.42 \%, 42.53 \%$ and $14.05 \%$ respectively (Azrina et al., 2010). As shown in Table 1, recent quantification of dabai flesh oil extract was studied using supercritical carbon dioxide method showed detailed profiling of fatty acids content. Thus, dabai possess comparable nutrient content as palm olein which suitable substitute for conventional oils and in the production of soap and shampoo (Azrina et al., 2010). Besides, fatty acids composition from the analysis of kernel oil of dabai showed that it is similar to cocoa butter, suggesting the oil as a cocoa butter equivalent (CBE). The results were oleic acid as the main constituent of monounsaturated lipids $(41.9 \%)$ while polyunsaturated linoleic acid was in a small amount $(14.05 \%)$. The significant saturated fatty acid present in dabai kernel oil is palmitic acid (40.31\%) with a small amount of myristic acid, stearic acid and arachidic acid (Liew et al., 2011).

\section{Health implication}

Dabai has been known to be a nutritious fruit that comprises $22.1 \%$ of carbohydrate, $339 \mathrm{kcal}$ of energy, $3.8 \%$ of protein and $26.2 \%$ of fat (Voon and Kueh, 1999). Besides being nutritious, it is also considered a healthy fruit due to its relatively high content of vitamin E. Oil is extracted by petroleum ether from both the dabai flesh and seed shows that there was about 12.04 $\mathrm{mg} / 100 \mathrm{~g}$ of vitamin $\mathrm{E}$ in dabai seed oil while none was detected from dabai flesh oil. There are eight different forms of vitamin $\mathrm{E}$ yet the focus is only on $\alpha$-tocopherol and $\gamma$-tocopherol. $\alpha$-tocopherol is a form that can normally be found in our body due to the fact that our body absorbs it and is abundant in olive and sunflower oil. The $\gamma$-tocopherol, on the other hand, is also found in our body but it depends on a person's diet and is abundant in the plant such as corn oil and soybean. The $\gamma$ -tocopherol has distinctive chemical properties that enable it to react with nitrogen dioxide which is a toxic compound that is needed to get rid of our body. The $\alpha-$ tocopherol produces nitrosating agent, an agent that may further react with amines to form nitrosamines that are carcinogenic after undergoing a chemical reaction with nitrogen dioxide while $\gamma$-tocopherol does not produce nitrosating agent when reacting with nitrogen dioxide (Cooney et al., 1993). Apart from that, $\alpha$-tocopherol is a potential antioxidant where it plays an important role as a radical-chain breaking antioxidant in both membranes and lipoprotein. This makes $\alpha$-tocopherol possess the potential to lower the risk of having cardiovascular diseases. Besides $\alpha$-tocopherol, $\gamma$-tocopherol are better in lowering the aggregation of platelets, slows the formation of thrombus intra-arterial, and also the oxidation of low-density lipoprotein (Schwartz et al., 2008). An ANOVA test has been carried out and depicted that dabai seed oil has a significantly higher 
Table 1. Fatty acids profile in Dabai flesh oil extract (Khoo et al., 2019).

\begin{tabular}{|c|c|c|c|}
\hline Carbon & FAMEs & $\%$ in fat & $\mathrm{Mg} / 100$ \\
\hline $\mathrm{C} 8$ & Caprylic & $0.05 \pm 0.00$ & $47.94 \pm 2.00$ \\
\hline $\mathrm{C} 10$ & Capric & $0.01 \pm 0.00$ & $5.99 \pm 0.14$ \\
\hline $\mathrm{C} 11$ & Undecanoic & $0.01 \pm 0.01$ & $9.50 \pm 6.76$ \\
\hline $\mathrm{C} 12$ & Lauric & $0.72 \pm 0.07$ & $694.46 \pm 38.38$ \\
\hline $\mathrm{C} 13$ & Tridecanois & $0.00 \pm 0.00$ & $3.81 \pm 0.66$ \\
\hline $\mathrm{C} 14$ & Myristic & $0.28 \pm 0.00$ & $270.41 \pm 10.39$ \\
\hline $\mathrm{C} 15$ & Pentadecanoic & $0.03 \pm 0.00$ & $25.42 \pm 1.27$ \\
\hline $\mathrm{C} 16$ & Palmitic & $41.53 \pm 0.13$ & $40273.79 \pm 1517.22$ \\
\hline $\mathrm{C} 17$ & Heptadecanoic & $0.11 \pm 0.00$ & $108.37 \pm 5.49$ \\
\hline $\mathrm{C} 18$ & Stearic & $4.31 \pm 0.01$ & $4175.36 \pm 167.51$ \\
\hline $\mathrm{C} 20$ & Arachidic & $0.10 \pm 0.00$ & $93.08 \pm 4.36$ \\
\hline $\mathrm{C} 21$ & Henicosanoic & $0.02 \pm 0.01$ & $18.51 \pm 11.23$ \\
\hline $\mathrm{C} 22$ & Beheric & $0.25 \pm 0.07$ & $245.22 \pm 77.32$ \\
\hline $\mathrm{C} 23$ & Tricosanoic & $0.11 \pm 0.00$ & $106.69 \pm 1.89$ \\
\hline $\mathrm{C} 24$ & Lignoceric & $0.10 \pm 0.01$ & $97.12 \pm 16.33$ \\
\hline \multicolumn{2}{|c|}{ Total Saturated fatty acid } & $47.62 \pm 0.13$ & $46175.65 \pm 1746.62$ \\
\hline $\mathrm{C} 14: 1$ & Myristoleic & $0.04 \pm 0.00$ & $40.51 \pm 0.3$ \\
\hline C15:1 & Cis-10-pentadecanoic & $0.04 \pm 0.00$ & $34.59 \pm 0.97$ \\
\hline C16:1 & Palmitoleic & $0.64 \pm 0.01$ & $615.88 \pm 24.31$ \\
\hline C17:1 & Cis-10-heptadecanoic & $0.03 \pm 0.00$ & $25.20 \pm 0.97$ \\
\hline $\mathrm{C} 18: \ln 9 \mathrm{c}$ & Oleic & $38.79 \pm 0.01$ & $37616.98 \pm 1541.0$ \\
\hline $\mathrm{C} 20: \ln 9$ & Cis-11-eicosenoic & $0.07 \pm 0.01$ & $29.41 \pm 41.58$ \\
\hline $\mathrm{C} 22: \ln 9$ & Erucic & $0.04 \pm 0.03$ & $39.27 \pm 27.63$ \\
\hline $\mathrm{C} 24: 1$ & Nervonic & $0.30 \pm 0.13$ & $289.66 \pm 146.71$ \\
\hline \multicolumn{2}{|c|}{ Total Monounsaturated fatty acid } & $39.93 \pm 0.16$ & $38691.48 \pm 1783.48$ \\
\hline $\mathrm{C} 18: 2 \mathrm{n} 6 \mathrm{c}$ & Linoleic (cis) & $11.95 \pm 0.01$ & $11593.46 \pm 456.69$ \\
\hline C18:3n6 & y-linoleic & $0.11 \pm 0.00$ & $103.92 \pm 1.88$ \\
\hline $\mathrm{C} 18: 3 \mathrm{n} 3$ & a-linoleic & $0.40 \pm 0.00$ & $387.11 \pm 15.2$ \\
\hline $\mathrm{C} 20: 4 \mathrm{n} 6$ & Arachidonic & $0.02 \pm 0.01$ & $14.71 \pm 4.12$ \\
\hline \multicolumn{2}{|c|}{ Total Polyunsaturated fatty acid } & $12.48 \pm 0.01$ & $12099.20 \pm 477.88$ \\
\hline
\end{tabular}

content of vitamin E compared to olive oil. A preliminary study was made where the different parts of dabai fruit were analysed for antioxidant properties (Jelani et al., 2017). Based on the $\beta$-carotene bleaching assay, the highest antioxidant activity was observed in the skin of dabai, with mean antioxidant activity of $89.31 \%$ O.I. The total phenolic content was higher in the skin and whole fruit with 25.07 and $5.43 \mathrm{mg}$ GAE/dried sample respectively, compared to the flesh $(3.38 \mathrm{mg}$ GAE/g dried sample) and kernel (2.14 mg GAE/g dried sample).

A study of defatted dabai parts was found to be rich in phenolics. Later led to another investigation on potential cholesterol-lowering agents due to their high antioxidant capacity (Shakirin et al., 2012b). The results showed that cholesterol-lowering effects were observed on hypercholesterolemic rabbits fed with a diet containing defatted flesh of dabai. Although different parts of dabai fruit have also been tested the positive effect from the flesh may suggest the presence of $70 \mathrm{mg}$ of polyphenolic compounds and high dietary fibre explained the effect (Khoo et al., 2015). In a recent study of the health impact of dabai, the extracts of dabai leaves can reduce the glucose level in streptozotocin-induced (STZ) Sprague-Dawley (Saari et al., 2017). This depicts the possibility of dabai leaves affecting blood glucose regulation in STZ-induced rats. Flavonoids, saponins, and terpenoids may be the attributes to the hypoglycaemic effect from the aqueous extract of dabai leaves. This hypoglycaemic effect can restore the function of pancreatic tissue to produce insulin or limit the absorption of glucose by the intestine (Malviya et al., 2010).

\section{Conclusion}

The three different parts of dabai namely skin, flesh, and seed have different nutritional properties and health impacts. A most significant event of dabai would be the increase of high-density lipoprotein and subsequently decrease low-density lipoprotein by dabai extract as high cholesterol levels are harmful to our health. In addition to that, dabai has the anti-hyperglycaemic effect by 
lowering blood glucose levels. Recently, quite a substantial amount of the fruit is now available in many forms from food products to attractive merchandise like handmade keychains from its seed. It is expected that the promising economic potential and commercialisation activity of dabai will increase substantially in the future. Dabai soon will be one of the priority crops of Sarawak and will be ranked with other fruits in the world market.

\section{Conflict of interest}

Authors declare no conflict of interest.

\section{Acknowledgments}

The research work was funded by Fundamental Research Grant Scheme (FGRS/1/2019/WAB01/ UPM/02/19/5540333). The authors would like to express special appreciation to the staffs of the Department of Crop Science, Faculty of Agricultural Science and Forestry for the completion of this study. Heartfelt gratitude to all colleagues for their generous contribution in manuscript assistance and thoughtful editing in this review.

\section{References}

Ali-Hassan, S.-H., Fry, J.R. and Abu Bakar, M.-F. (2013). Antioxidative phytochemicals and anticholinesterase activity of native kembayau (Canarium odontophyllum) fruit of Sabah, Malaysian Borneo. Journal of Nutrition and Food Sciences, 4(1), $1000249 . \quad \mathrm{https} / /$ doi.org/10.4172/2155-9600.1000249.

Azlan, A., Prasad, K.N., Khoo, H.E., Abdul-Aziz, N., Mohamad, A., Ismail, A. and Amom, Z. (2010). Comparison of fatty acids, vitamin $\mathrm{E}$ and physicochemical properties of Canarium odontophyllum Miq. (dabai), olive and palm oils. Journal of Food Composition and Analysis, 23(8), 772-776. https://doi.org/10.1016/j.jfca.2010.03.026

Azrina, A., Nadiah, M.N. and Amin, I. (2010). Antioxidant properties of methanolic extract of Canarium odontophyllum fruit. International Food Research Journal, 17(2), 319-326.

Brooke, P. and Lau, C.Y. (2013). Dabai planting material and propagation technique, p. 1-6. Sarawak, Malaysia: Jabatan Pertanian Sarawak

Brooke, P., Yuon, L.C. and Rajmah, M.R. (2013). Experience in commercialising Canarium odontophyllum Miq.: A potential superfruit of Sarawak, presented at the International Symposium on Superfruits: Myth or Truth, 1 - 3 July 2013. Vietnam
Codex Alimentarius Commission (2019). Codex Stan 19: edible fats and oils not covered by individual standards. Retrieved on 02 October 2017 from Food and Agriculture Organization of the United Nations website: http://www.fao.org/fao-whocodexalimentarius/codex-texts/list-standards/en/

Cometh. (2008). Dabai Seed. Retrieved on 28 August, 2017 from redbubble website: https:// www.redbubble.com/people/cometh/works/1306342 -dabai-seed

Cooney, R.V., Franke, A.A., Harwood, P.J., HatchPigott, V., Custer, L.J. and Mordan, L.J. (1993). Gamma-tocopherol detoxification of nitrogen dioxide: superiority to alpha-tocopherol. Proceedings of the National Academy of Sciences, 90(5), 1771-1775. https://doi.org/10.1073/ pnas.90.5.1771.

Ding, P. and Tee, Y.K. (2011). Physicochemical characteristics of dabai (Canarium odontophyllum Miq.) fruit. Fruits, 66(1), 47-52. https:// doi.org/10.1051/fruits/2010040.

Emmet. (2017). 10 jenis buah popular di pasar tamu Sarawak. Retrieved on 25 December, 2020 from Cikgu Emmet Menulis website: https:// cikguemmet.com/2017/07/10-jenis-buah-popular-dipasar-tamu-sarawak/ [In Bahasa Malaysia].

Fazlisham. (2010). Meneroka potensi buah Dabai Sarawak. Retrieved on 25 December, 2017 from Segalanya Tentang Tumbuhan website: http:// fazlisyam.com/meneroka-potensi-buah-dabaisarawak/ [In Bahasa Malaysia].

Hoe, V.B. and Siong, K.H. (1999). The nutritional value of indigenous fruits and vegetables in Sarawak. Asia Pacific Journal of Clinical Nutrition, 8(1), 24-31.

Jelani, N.A.A., Azlan, A., Ismail, A., Khoo, H.E. and Alinafiah, S.M. (2017). Fatty acid profiles and antioxidant properties of dabai oil. ScienceAsia, 43 (6), 347-353.

Johnson, E.J. (2002). The role of carotenoids in human health. Nutrition in Clinical Care, 5(2), 56-65. https://doi.org/10.1046/j.1523-5408.2002.00004.x.

Khoo, H. E., Azlan, A., and Abd Kadir, N.A.A. (2019). Fatty acid profile, phytochemicals, and other substances in Canarium odontophyllum fat extracted using supercritical carbon dioxide. Frontiers in Chemistry, 7, 5. https://doi.org/10.3389/ fchem.2019.00005

Khoo, H.E., Azlan, A., Ismail, A. and Al-Sheraji, S.H. (2015). Protective effects of defatted dabai peel extract in hypercholesterolemic rabbits based on histopathological methods. Malaysian Journal of Medicinal and Health Science, 11(2), 59-68. 
Lau, C.Y. (2009). Development of indigenous fruit crops in Sarawak. A case study on dabai fruit, presented at Proceedings of the National Conference on New Crops and Bioresources, 15-17 December, p. 15-20. Negeri Sembilan, Malaysia.

Lau, C.Y. (2011). Emas hitam Sarawak. In Laman Impiana Mei-Jun, p. 46-47. [In Bahasa Malaysia].

Lau, C.Y. and Voon, B.H. (2007). New dabai clones. Sarawak, Malaysia: Department of Agriculture.

Leenhouts, P.W., Kalkman, C. and Lam, H.J. (1956). Burseraceae. Canarium. Series 1. Flora Malesiana, 5 (1), 249-296.

Lemmens, R., Soerianegara, I. and Wong, W.C. (1995). Plant resources of South. East Asia, 5(2), 59-70.

Liew, C.Y., Lau, C.Y., Rajmah, M.R., Rahimah, S. and Liew, S.M. (2011). Nutritional, physical and sensory analysis of processed dabai kernel, presented at Proceeding Research Officers' Progress Meeting, Sarawak, 5-6 October, 2011. Sarawak, Malaysia: Department of Agriculture.

Lim, T.K. (2012). Edible medicinal and non-medicinal plants. Volume 2, Fruits. Switzerland: Springer. https://doi.org/10.1007/978-94-007-1764-0

Machabuca. (2015). Canarium odontophyllum - Brunei Olive. Retrieved on 31 December 2017 on website: https://www.flickr.com/ photos/69028902@N00/20500644839

Malaysian Agricultural Research and Development Institute (MARDI). (2017). Dabai, specialty fruit of Sarawak. Retrieved on 25 December 2020 on Blog Rasmi MARDI website: https:// blogmardi.wordpress.com/2017/02/13/dabaispecialty-fruit-of-sarawak/

Malviya, N., Jain, S. and Malviya, S. (2010). Antidiabetic potential of medicinal plants. Acta Poloniae Pharmaceutica, 67(2), 113-118.

McCauley, G. (2010). The ancient olive. Retrieved on 20 November, 2017 on My Algarve website: https:// myalgarve.wordpress.com/2010/08/18/the-ancientolive/

Mokiran, N.N., Ismail, A., Azlan, A., Hamid, M., and Hassan, F.A. (2014). Effect of dabai (Canarium odontophyllum) fruit extract on biochemical parameters of induced obese-diabetic rats. Journal of Functional Foods, 8, 139-149. https:// doi.org/10.1016/j.jff.2014.03.007.

Nayra, A. (2017). Someone actually turned dabai into ice cream. Retrieved on 10 September, 2017 on Instagram website: https:/www.instagram.com/ lyfeisnteasy/

NCL GoldenTrove Sdn Bhd. (2012). Dabai - Sold Fresh Frozen. Retrieved on 9 September, 2017 on NCL
GoldenTrove

website:

http://

site.nclgoldentrove.org.my/main/3084/index.asp?

pageid $=129264 \& \mathrm{t}=$ dabai---sold-fresh-frozen

Nimi. (2013). Dabai fruit and dabai fried rice. Retrieved on 25 December 2017 on Sarawak Ethnic Cuisine website: http://www.huntersfood.com/2013/11/buahdabai-nasi-goreng-dabai.html

Prasad, K.N., Chew, L.Y., Khoo, H.E., Yang, B., Azlan, A. and Ismail, A. (2011). Carotenoids and antioxidant capacities from Canarium odontophyllum Miq. Fruit. Food Chemistry, 124(4), 1549-1555.

https://doi.org/10.1016/

j.foodchem.2010.08.010.

Saari, S.M., Basri, D.F., Budin, S.B. and Warif, N.M.A. (2017). Effects of Canarium odontophyllum leaves on plasma glucose and $\mathrm{T}$ lymphocyte population in streptozotocin-induced diabetic rats. Saudi Journal of Biological Sciences, 24(2), 320-323. https:// doi.org/10.1016/j.sjbs.2015.09.032.

Schwartz, H., Ollilainen, V., Piironen, V. and Lampi, A.M. (2008). Tocopherol, tocotrienol and plant sterol contents of vegetable oils and industrial fats. Journal of Food Composition and Analysis, 21(2), 152-161. https://doi.org/10.1016/j.jfca.2007.07.012.

Shakirin, F.H., Azlan, A., Ismail, A., Amom, Z. and Yuon, L.C. (2012b). Protective effect of flesh oil extracted from Canarium odontophyllum Miq. fruit on blood lipids, lipid peroxidation, and antioxidant status in healthy rabbits. Malaysian Journal of Medicine and Health Sciences, 11(2), 59-68.

Shakirin, F.H., Azlan, A., Ismail, A., Amom, Z. and Yuon, L.C. (2012a) Antiatherosclerotic effect of Canarium odontophyllum Miq. fruit parts in rabbits ded high cholesterol diet. Evidence-Based Complementary and Alternative Medicine, 2012, 838604 . https://doi.org/https:// doi.org/10.1155/2012/838604.

Sim, S.L. and Lau, C.Y. (2011). Floral biology of dabai. New Sunday Tribune. Sarawak.

Voon, B.H. (2003). Indigenous fruits for commercial exploitation, presented at House Seminar on New Crops with Potential for Commercialisation, p. 57. Sarawak, Malaysia: Department of Agriculture.

Voon, B.H. and Kueh, H.S. (1999). The nutritional value of indigenous fruits and vegetables in Sarawak. Asia Pacific Journal of Clinical Nutrition, 8(1), 24-31. https://doi.org/10.1046/j.1440-6047.1999.00046.x. 